\title{
Study on the Paradigm of the Secondary Vocational School's E-commerce Specialty Based on the Reform of CDIO Teaching Model
}

\author{
Min Wang ${ }^{1, a}$,Xiaohui $\mathrm{Hu}^{2, b}$, Fuchang $\mathrm{Li}^{3, \mathrm{c}^{*}}$, jia Shi ${ }^{4, \mathrm{~d}}$ \\ 1 School of Economics \& Management, Yunnan Normal University postgraduate (student), China \\ ${ }^{2}$ School of Economics \& Management, Yunnan Normal University, associate research fellow,China \\ ${ }^{3}$ School of Economics \& Management,Yunnan Normal University, Professor, China \\ ${ }^{4}$ Shan Dong University School of Foreign Languages, postgraduate (student), China \\ a2313170301@qq.com, b75042344@qq.com, c24695192@qq.com, d3268369489@qq.com \\ ${ }^{*}$ Corresponding author
}

Keywords: CDIO, secondary vocational e-commerce, paradigm research

\begin{abstract}
This paper studies the evolution of the teaching reform of e-commerce in secondary vocational colleges from the perspective of paradigm theory. Based on the fusion innovation under the framework of CDIO engineering education model, the paradigm perspective combines the actual creation of the $\mathrm{X}+\mathrm{CDIO}$ model to form the PDCI cycle and the CMM maturity model. It has a positive impact on the educational ecology and educational efficiency in teaching reform.
\end{abstract}

\section{Kuhn paradigm theory}

Under the circumstance of historical change and globalization in China, secondary vocational education is facing reform. From the perspective of the overall macro system, in fact, it can also be seen as a paradigm-compatible. Kuhn believes that in the description and interpretation of scientific viewpoints, what really needs to be done and what can be done are the value selection work in psychology and sociology. In such work, the "paradigm" thought is more real and effective than the generalized logic rules, At present, the academic circles discuss the "educational research paradigm". In terms of content, educational researchers agree that educational beliefs, as the main factors of formation are directly related to educational researchers' understanding of the nature of educational ontology and epistemology. The problem of procedures and methods, that is, the ultimate goal of the research paradigm lies in the practical level of educational research, which can be said to be the external manifestation of the research paradigm.

\section{CDIO engineering education model}

Different educational beliefs will have corresponding research procedures and methods. Secondary vocational colleges mainly train professional talents for the society, and improve the secondary vocational education under the systematic paradigm of work process. Under the current social situation, the integration of vocational education requires sociology, psychology and paradigm thinking to be integrated into practical education to constantly explore new path adapting to the students' development. The curriculum teaching paradigm has an important influence on the attraction and pro-minority of ideological and political theory courses. how should we establish a talent training system and what kind of functional transformation? The CDIO engineering education model represents Conceive, Design, Implement, and Operate. CDIO's curriculum design is based on a comprehensive analysis of talent training objectives. It mainly includes four aspects: technical knowledge and reasoning, personal and vocational skills, interpersonal skills and CDIO system.

\section{Secondary vocational school e-commerce major}

This paper uses the reverse design thinking method to set up the evaluation feedback link in CDIO, 
that is, the idea of the first educational goal in the e-commerce major of secondary vocational schools, bring it to the enterprise for training and visit, and the students get feedback information, what is the key point? What is the necessary skills in the future, and then come to the classroom to study the curriculum, the current reform and innovation is the "engineering paradigm" - "paradigm shift" - "design paradigm" mode, the actual vocational e-commerce professional is CEDIO, evaluate; Including the student evaluation, enterprise evaluation and school evaluation, in this cycle, a small ecological chain, software and hardware reorganization, and the integration of the curriculum will be realized. In the integration of teaching, the school-based teaching materials should be fully developed, and the teachers' quality and ability should be a combination of local features, In connection with the paradigm thinking of fusion innovation, On this basis, we will establish a good anti-"feedback evaluation-reform and improvement" mechanism

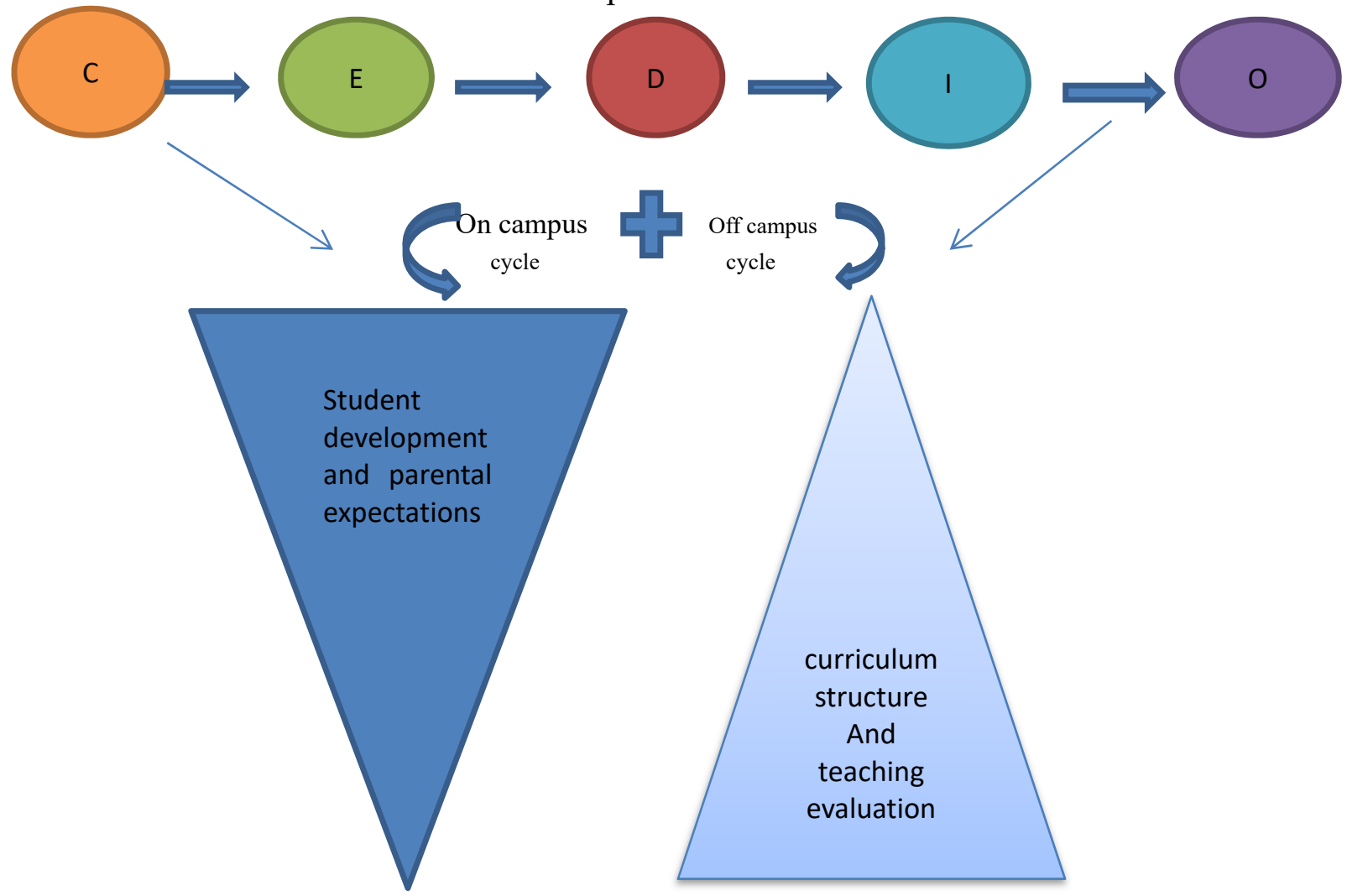

Figure 1 Paradigm reform system fishbone diagram

Students can form R-D-D-D course modules in the study, the research cycle is research, development, demonstration, dissemination, including e-commerce students to define the market needs, look at the market in enterprise learning, and position their career planning; Teachers help students to find innovative points to develop design learning plans and curriculum modules; in-depth consideration of student needs, identify their own characteristics, verify the potential of students in the curriculum and classroom; graduation results display.

\section{Based on the fusion innovation paradigm metamorphosis theory}

Studying the trajectory of the paradigm of education, can be explored with supply and demand-driven experience, whether it is the evolution of work style or student learning under modern information technology, in the paradigm of PBL teaching mode, OBE teaching mode and CDIO engineering education mode Development, including improvements in the input and output of education, from the urban-rural dual gap to educational equity and educational efficiency, Reflecting the mold period of paradigm theory, Kant's absolute command speaks the highest law of universal command, and the vocational e-commerce teaching also embodies the law of education in the paradigm reform. Quine's ontology promises to answer the teaching process in the law of 
education. The new product is updated, the new concept is injected into the new principle of evaluation and reform, Preview+CDIO mode. In practice, the teaching process needs to be previewed to realize the development of teaching activities, and the final paradigm evolves into the ecological circle, namely Ecology+CDIO mode;

\section{Summary}

Mould+CDIO forms a model teaching, forming a virtuous circle in the rhythm, especially the rhythm teaching in the e-commerce classroom has a positive effect on the overall development, but also according to the characteristics of students, and finally in the depth of knowledge. Based on the actual fusion innovation, and finally feedback to the classroom in the teaching evaluation, under the guidance of Marxism and social science methodology, we explore the reform of the teaching model in the perspective of methodology, and carry out the "online + offline" joint, Teaching, the student's moral education activity section has also been greatly strengthened. In the context of teaching reform under the background of informatization, focus on exploring high-efficiency paradigms and virtual simulation practice teaching, in which students learn to self-manage; in the Capability Maturity Model, introduce the ability assessment and promotion of teachers in teaching reform, In the maturity test, it is divided into step-by-step running-in, in the middle-level e-commerce practice system:
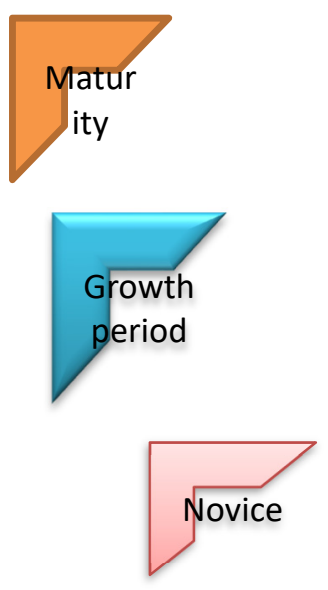

Teacher CDIO ability

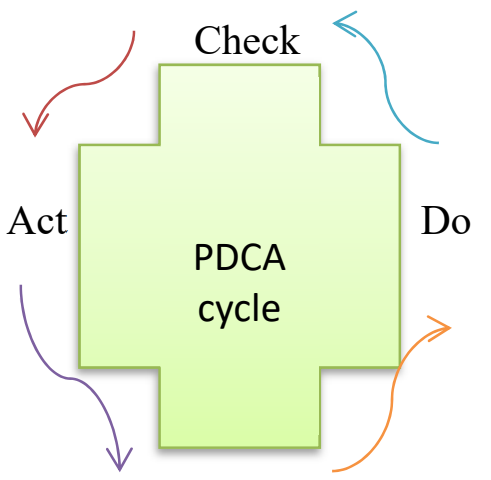

Plan
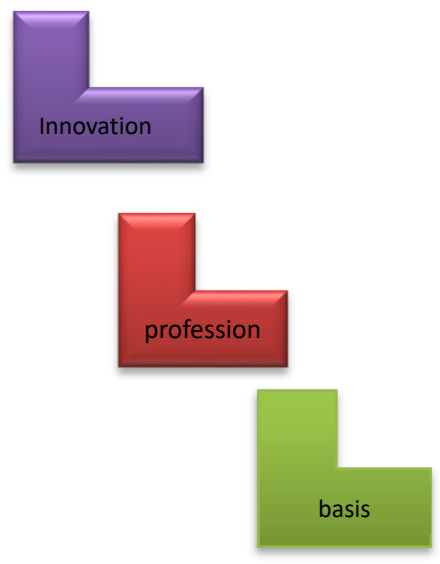

Student CDIO ability

Figure 2 Teacher and student CDIO mutual improvement system and CMM model

According to the qualitative research of the whole model, the theory of roots is studied, the paradigm is studied in the new ideas and reforms, the learning atmosphere of the whole profession is improved, the construction of the mature model of CMM ability is combined with the actual situation of the school, and the long-tail effect of the new business form in the context of informationization is faced. For the analysis of flexibility, Read the CDIO teaching mode of the secondary vocational e-commerce, establish a long-term incentive mechanism and a core system evaluation feedback mechanism, study the problems of education under the reform framework, and move from classroom to practice.

\section{Acknowledgments}

I am very grateful to the anonymous editors and corresponding authors. This research is supported by the national natural science foundation of China $(71562036,71362028)$; Yunnan philosophy and social science education science planning project (AD18012);Education program of industry-university cooperation of the ministry of education (201802098054); Scientific research fund project of yunnan provincial department of education (2018JS140). 


\section{References}

[1] YE Shubin. The Paradigm Shift and Innovation of Marxism in China[J].Chongqing Social Sciences,2017(07):16-23.

[2] Luo Shengquan. Review and Prospect of the 70-year Curriculum Research Paradigm [J/OL]. Journal of Educational Science of Hunan Normal University: 1-12[2019-05-18].http://kns.cnki.net/kcms/Detail/43.1381.G4.20190514.1620.028.html. 